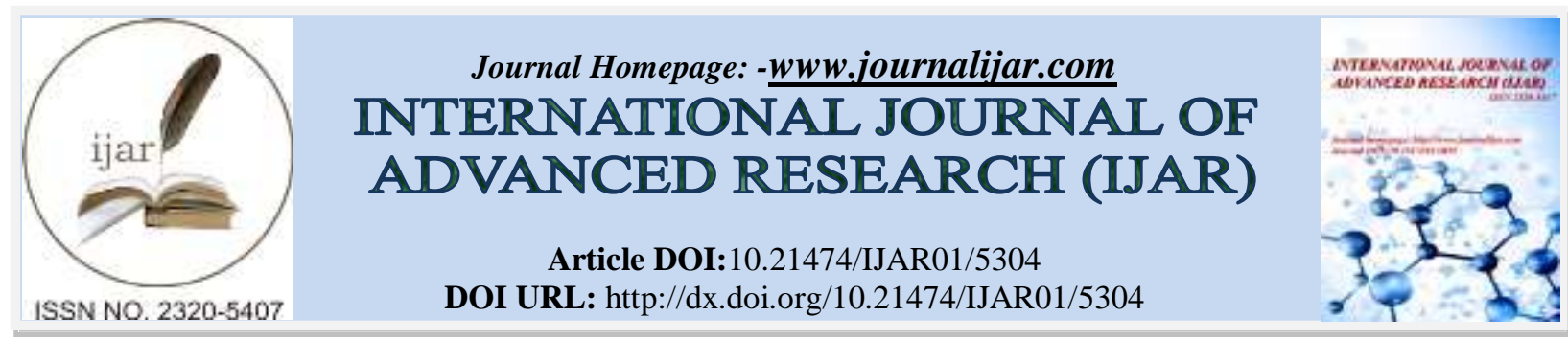

RESEARCH ARTICLE

\title{
SYNTHESIS AND CHARACTERIZATION OF A NEW BIOACTIVE MANNICH BASE MORPHOLINO METHYL MALEIC HYDRAZIDE (MMMH).
}

\section{P. R. Santhi ${ }^{1}$, G. Selvanathan ${ }^{1}$ and G. Poongothai ${ }^{2}$.}

1. Department of chemistry,A.V.C College(Autonomous),Mannampandal,Mayiladuthurai, Tamilnadu, India.

2. Department of chemistry ,Government Arts College for Men (Autonomous), Nandanam, Chennai35,Tamilnadu,India.

\section{Manuscript Info}

Manuscript History

Received: 02 July 2017

Final Accepted: 04 August 2017

Published: September 2017

Key words:-

Mannich base, MMMH, IR,NMR Mass spectrum.

\begin{abstract}
In this study a new N-Mannich base Morpholino Methyl Maleic Hydrazide (MMMH) was synthesized by introducing morpholinomethyl moiety in place of active hydrogen atom attached to nitrogen of maleichydrazide through Mannich reaction. The newly synthesized mannich base structure was characterized by elemental analysis,IR,UV-Visible,NMR and Mass spectra.Based on the spectral and analytical data the structure of the N-Mannich base was confirmed.
\end{abstract}

Copy Right, IJAR, 2017,. All rights reserved.

\section{Introduction:-}

The Mannich reaction is a three component condensation in which a compound containing an active hydrogen (substrate) is allowed to react with formaldehyde and $\mathrm{NH}$-amine derivative. These three compounds condense with concomitant release water to produce a new base known as a mannich base in which active hydrogen atom is replaced by an aminomethylgroup.TheMannich reaction of maleic hydrazide and releated compounds are reported in the literature ${ }^{1}$.The synthesis of 1-morpholinomethyl-3-hydroxy-6-pyridazinone also known as Morpholinomethylmaleichydrazide (MMMH), was reported by Hellmann et $\mathrm{al}^{2}$ and Morpholine derivatives were reported by $\mathrm{Lan}^{3}$, Reppart ${ }^{4}$ and Wang et $\mathrm{l}^{5}$. Though it was reported in the literature,complete characterization of MMMH including single crystal analysis was not attempted.So an attempt was made to synthesiseMorpholinomethylmaleichydrazide $(\mathrm{MMMH})$ by modifying the procedure given in the literature in order to improve its yield and crystalline nature using Mannichreaction. The structure of maleichydrazide and the synthesized Mannich base are given in Figs-1,2.

Experimental:-

Chemicals:

Maleichydrzide (99\% pure), Formaldehyde, Morpholine( $99 \%$ pure) were used as supplied.All other solvents were of A.R grade and used as such.

Physical measurements:

The elemental analysis were performed using LECO-CHN 600 Elemental Analyser and was calibrated using standard EDTA prier to the determination. The UV-Visible region was measured using JASCO UNIDEC-430 B double beam Spectrophotometer provided with quartz cells.IR spectral measurements was made for the ligand as $\mathrm{KBr}$ pellets using Perkin Elmer 1430 Ratio Recording Spectrometer.The ${ }^{1} \mathrm{H}$ and ${ }^{13} \mathrm{C}$ NMR of the ligand was recorded 
on BRUKER $400 \mathrm{MHz}$ Spectrometer.The Mass spectral study of the ligand was carried out using Finningin MAT8230 mass spectrometer.

2.3. Synthesis of Mannich base ${ }^{8,9}$

An equimolar mixture of maleichydrazide, formaldehyde and morpholine was dissolved in 400ml ethanol and refluxed for about five hours. The formation of the product $\mathrm{MMMH}$ and the completion of the reaction was identified by the formation of a clear solution. The resulting solution was concentrated to $200 \mathrm{ml}$ by distillation under reduced pressure. The concentrate on cooling yielded a colourless crystalline solid (Crude product $20.6 \mathrm{~g} ; 98 \%$ yield).

The crude product was first washed with ethanol and then ether and dried in vaccum oven. The compound was recrystallized from ethanol. It is freely soluble in cold water, soluble in hot methanol, ethanol and propanol. It is insoluble in chloroform, acetone and ether.

3.Results and Discussion

The results of the elemental analysis are given Table.1 which indicates the molecular formula $\mathrm{C}_{9} \mathrm{H}_{13} \mathrm{~N}_{3} \mathrm{O}_{3} . \mathrm{The}$ compound melts at $298^{\circ} \mathrm{C}$.

3.1.UV Spectrum ${ }^{7}$

The MMMH exhibits UV band at $337 \mathrm{~nm}$, which is assignable to $\pi-\pi^{*}$ transition of the carbonyl group. This occurs at a longer wavelength compared with maleichydrazide which indicates the derivatisation of the compound.

\subsection{IR Spectrum ${ }^{6,7}$}

The IR spectrum of MMMH is shown in Fig-3 and Table-2.A broad band appears at $3440 \mathrm{~cm}^{-1}$, which is due to $v_{\mathrm{O}-\mathrm{H}}$ and the other sharp bands at 2956 and $2417 \mathrm{~cm}^{-1}$ arise due to " $v_{\mathrm{CH}}$ " and $\mathrm{CH}_{2}$ groups respectively.

Sharp bands appearing at 1711 and 1612 are due to the $v_{\mathrm{C}=\mathrm{O}}$ and $\delta_{\mathrm{OH}}$ respectively. On comparing with the IR spectrum of maleichydrazide a new sharp and intense band at $1109 \mathrm{~cm}^{-1}$ is seen which can be assigned to the $v_{\mathrm{CNC}}$ of the morpholinemoiety. The appearance of this band confirms the insertion of the amino moiety into the pyridazine ring.

\section{3. ${ }^{1} \mathrm{H}$ and ${ }^{13} \mathrm{C}$ NMR Spectra ${ }^{7}$}

The ${ }^{1} \mathrm{H}$ NMR spectra of maleichydrazide and MMMH are shown in Figs-4,5 and Table-3.Five signals are observed in the NMR spectrum of morpholinomethylmaleichydrazide shows absence of signal due to N(1)H during Mannich condensation and the insertion of the morpholino methyl moiety at $\mathrm{N}(1) \mathrm{H}$ of maleichydrazide. The resonance signals appearing at 6.43,5.03,3.35-3.33 and 2.51-2.64 can be assigned to the vinyl protons $[\mathrm{HC}(4)=\mathrm{CH}(5) \mathrm{H}]$; Bridging protons $\mathrm{N}-\mathrm{CH}_{2}-\mathrm{N} ;-\mathrm{N}\left(\mathrm{CH}_{2}\right)_{2}$ and $-\left(\mathrm{CH}_{2}\right)_{2} \mathrm{O}$ respectively.

The ${ }^{13} \mathrm{C}$ NMR spectrum of MMMH is shown in Fig-6 and Table-3.Carbon chemical shift values are in close agreement with the structure proposed on the basis of ${ }^{1} \mathrm{H}$ NMR data.

3.4.Mass spectrum ${ }^{10}$

The mass spectrum of MMMH (Fig.7) exhibits the molecular ion peak at $\mathrm{m} / \mathrm{z}=211$ which corresponds to the proposed molecular mass of the compound.The fragmentation pattern is given in Fig.8.The above fragmentation pattern is in close agreement with the data obtained for MMMH.

\section{Conclusion:-}

A new mannich base Morpholinomethylmaleichydrazide has been synthesized and characterized by elemental analyses and spectural study.

Table 1:-Elemental analysis of MMMH

\begin{tabular}{|c|c|c|c|}
\hline Element & Carbon(\%) & Hydrogen $(\%)$ & Nitrogen(\%) \\
\hline Found & 51.20 & 6.20 & 19.89 \\
\hline Calculated & 51.18 & 6.16 & 19.91 \\
\hline
\end{tabular}


Table 2:- Important IR absorption bands $\left(\mathrm{cm}^{-1}\right)$ of Maleic hydrazide and MMMH

\begin{tabular}{|c|c|l|}
\hline MH & MMMH & \multicolumn{1}{|c|}{ Tentative assignment } \\
\hline $3428-2100(\mathrm{vb})$ & - & $\mathbf{v}_{\mathbf{O H}}, \mathbf{v}_{\mathbf{N H}}$ and $\mathbf{v}_{\mathbf{C H}}$ \\
\hline- & $3440-2500$ & $\mathbf{v}_{\mathbf{O H}}, \mathbf{v}_{\mathbf{C H}}$ \\
\hline 1645 & 1711 & $\mathbf{v}_{\mathbf{C O}}$ \\
\hline 1550 & 1612 & $\boldsymbol{\delta}_{\mathbf{O H}}$ \\
\hline 1309 & 1399 & $\mathbf{v}_{\mathbf{C}-\mathbf{C}}$ \\
\hline 1269 & 1273 & $\boldsymbol{\delta}_{\mathbf{C}-\mathbf{N}}$ \\
\hline 1010 & 1043 & $\mathbf{v}_{\mathbf{N}-\mathbf{N}}$ \\
\hline 813 & 760 & $\mathbf{v r i n g}$ \\
\hline 519 & 550 & $\mathbf{\delta C O}$ \\
\hline- & 1109 & $\mathbf{v}_{\mathbf{C}-\mathbf{N}-\mathbf{C}}$ \\
\hline
\end{tabular}

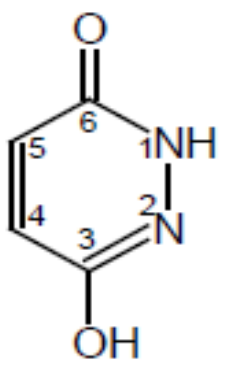

Fig1:- Maleic hydrazide

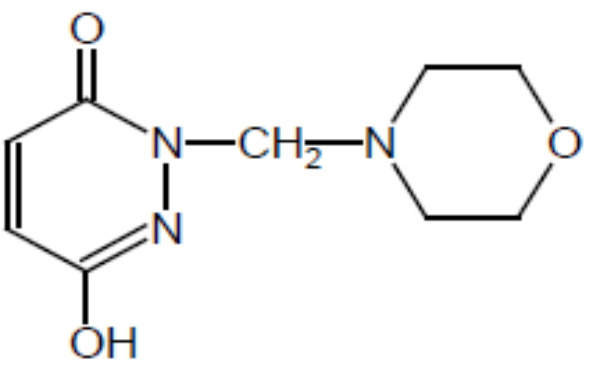

Fig.2.1:-Morpholinomethylmaleichydrazide

Fig.3:-IR Spectrum of MMMH

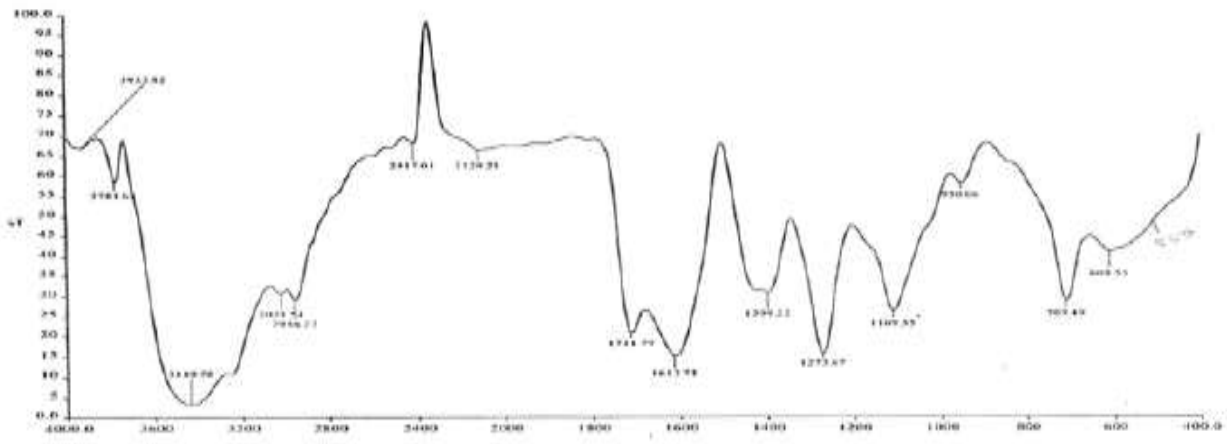

Fig.4:- ${ }^{1} \mathrm{H}$ NMR Spectrum of Maleic hydrazide

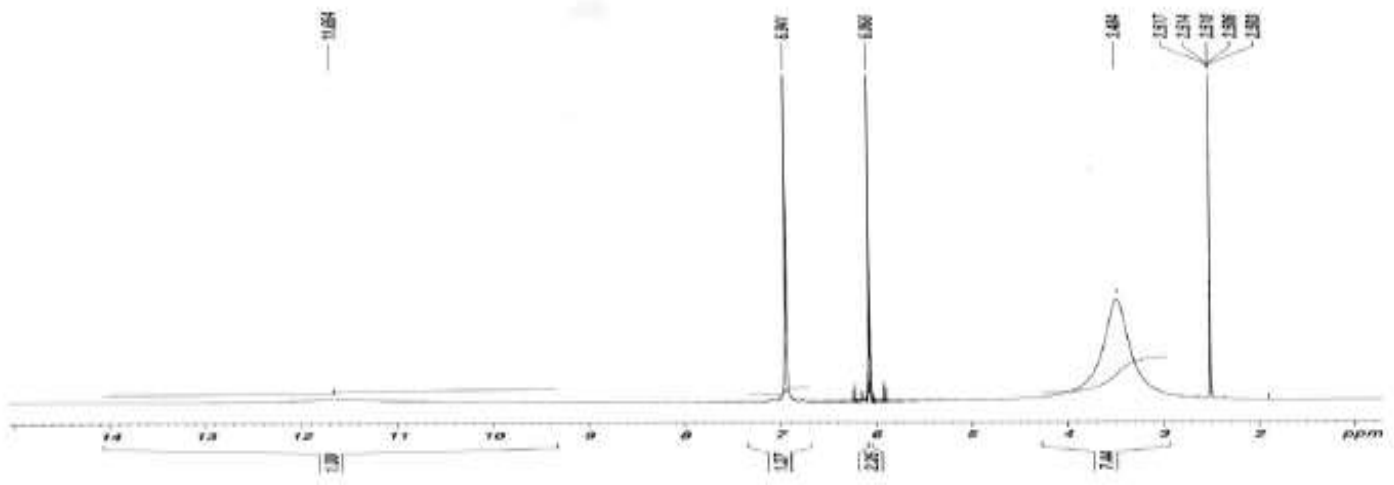


Table 3:- ${ }^{1} \mathrm{H}$ and ${ }^{13} \mathrm{C}$ NMR Spectra of maleic hydrazide (MH) and MMMH

\begin{tabular}{|c|c|c|c|c|}
\hline \multirow[t]{2}{*}{ Type of protons } & \multicolumn{2}{|c|}{ MH } & \multicolumn{2}{|c|}{ MMMH } \\
\hline & бppm & Multiplicity & бppm & Multiplicity \\
\hline $\mathrm{CH}=\mathrm{CH}$ & 6.03 & $\mathrm{~S}$ & 6.43 & $\mathrm{~S}$ \\
\hline $\mathrm{C}-\mathrm{OH}$ & 3.49 & $\mathrm{~S}$ & 3.72 & $\mathrm{~S}$ \\
\hline Solvent proton & 2.49 & - & - & - \\
\hline $\mathrm{N}-\mathrm{CH}_{2}-\mathrm{N}$ & - & - & 5.03 & $\mathrm{~S}$ \\
\hline$-\mathrm{N}\left(\mathrm{CH}_{2}\right)_{2}$ & - & - & $3.35-3.33$ & $\mathrm{~S}$ \\
\hline$-\left(\mathrm{CH}_{2}\right)_{2} \mathrm{O}$ & - & - & $2.51-2.64$ & $\mathrm{~d}$ \\
\hline Type of Carbons & \multicolumn{2}{|c|}{ Maleic hydrazide } & \multicolumn{2}{|c|}{ MMMH } \\
\hline $\mathrm{C}=\mathrm{O}$ & \multicolumn{2}{|c|}{167.26} & \multicolumn{2}{|c|}{174.72} \\
\hline $\mathrm{C}-\mathrm{OH}$ & \multicolumn{2}{|c|}{136.09} & \multicolumn{2}{|c|}{135.36} \\
\hline $\mathrm{HC}=\mathrm{CH}$ & \multicolumn{2}{|c|}{110.00} & \multicolumn{2}{|c|}{130.49} \\
\hline $\mathrm{N}-\mathrm{CH}_{2}-\mathrm{N}$ & \multicolumn{2}{|c|}{-} & \multicolumn{2}{|c|}{66.28} \\
\hline$-\mathrm{N}\left(\mathrm{CH}_{2}\right)_{2}$ & \multicolumn{2}{|c|}{-} & \multicolumn{2}{|c|}{50.09} \\
\hline$-\left(\mathrm{CH}_{2}\right)_{2} \mathrm{O}$ & \multicolumn{2}{|c|}{-} & \multicolumn{2}{|c|}{37.88} \\
\hline
\end{tabular}

Fig.5:- ${ }^{1} \mathrm{H}$ NMR Spectrum of MMMH

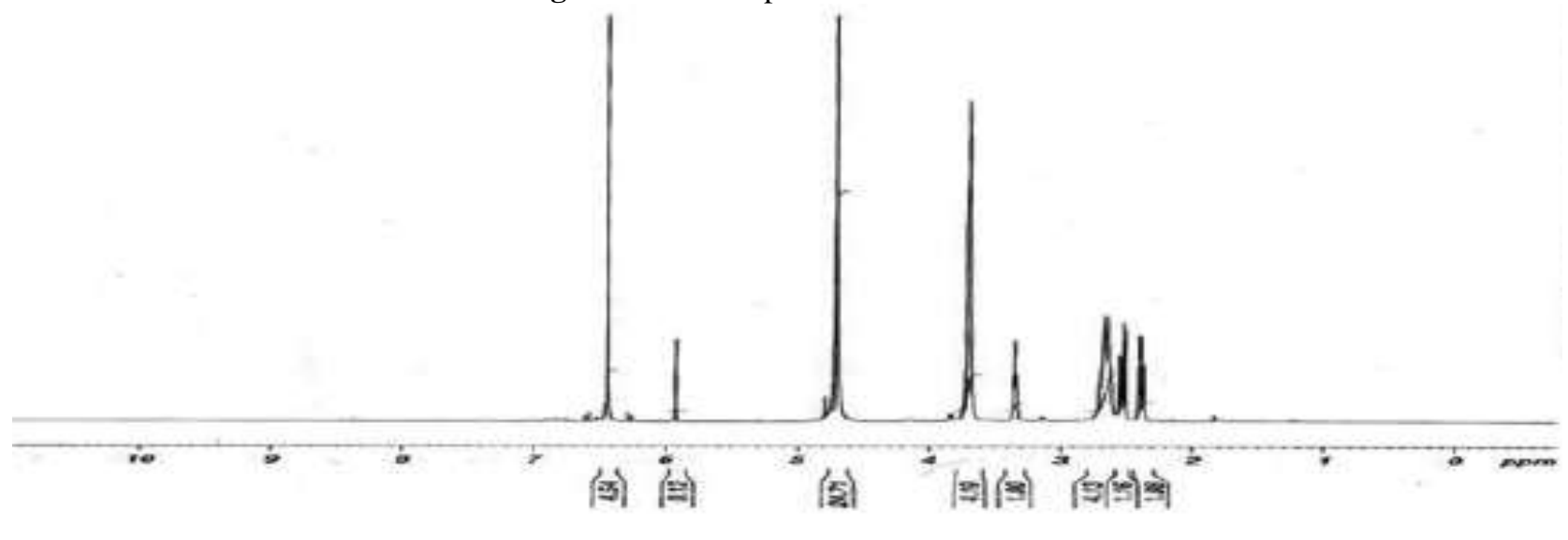

Fig.6:- ${ }^{13} \mathrm{C}$ NMR Spectrum of MMMH.

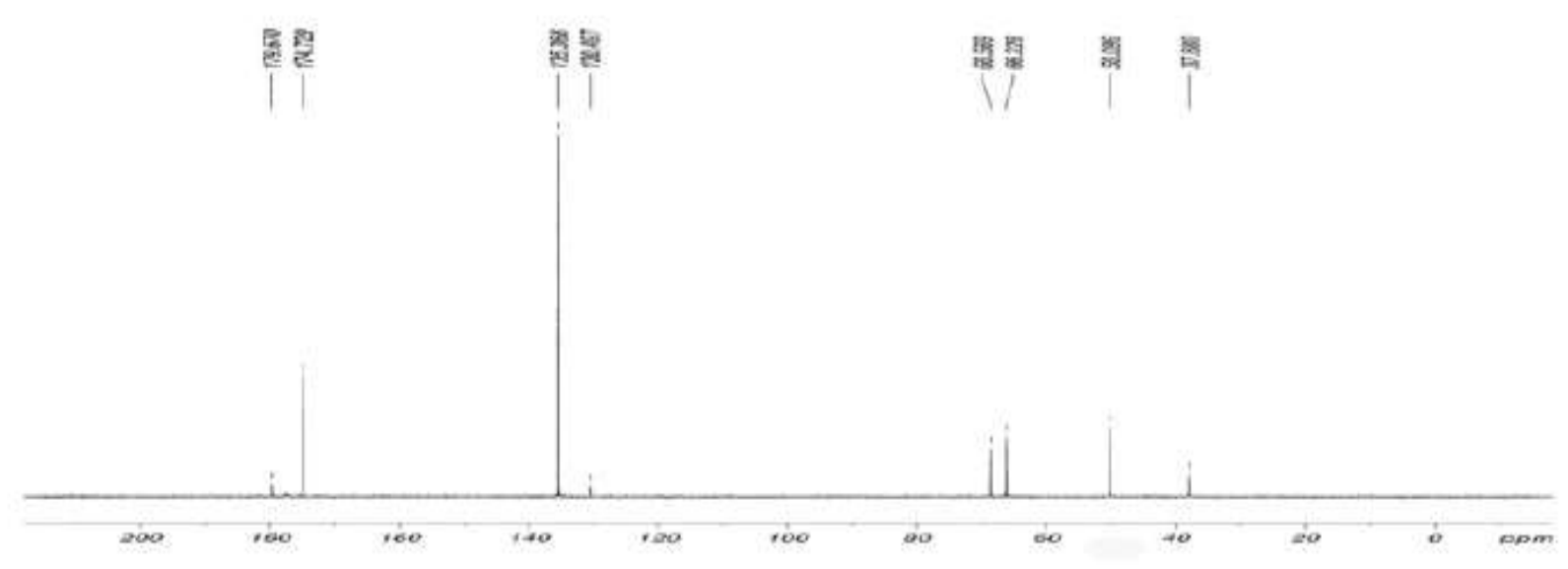


Fig.7:-Mass Spectrum of MMMH

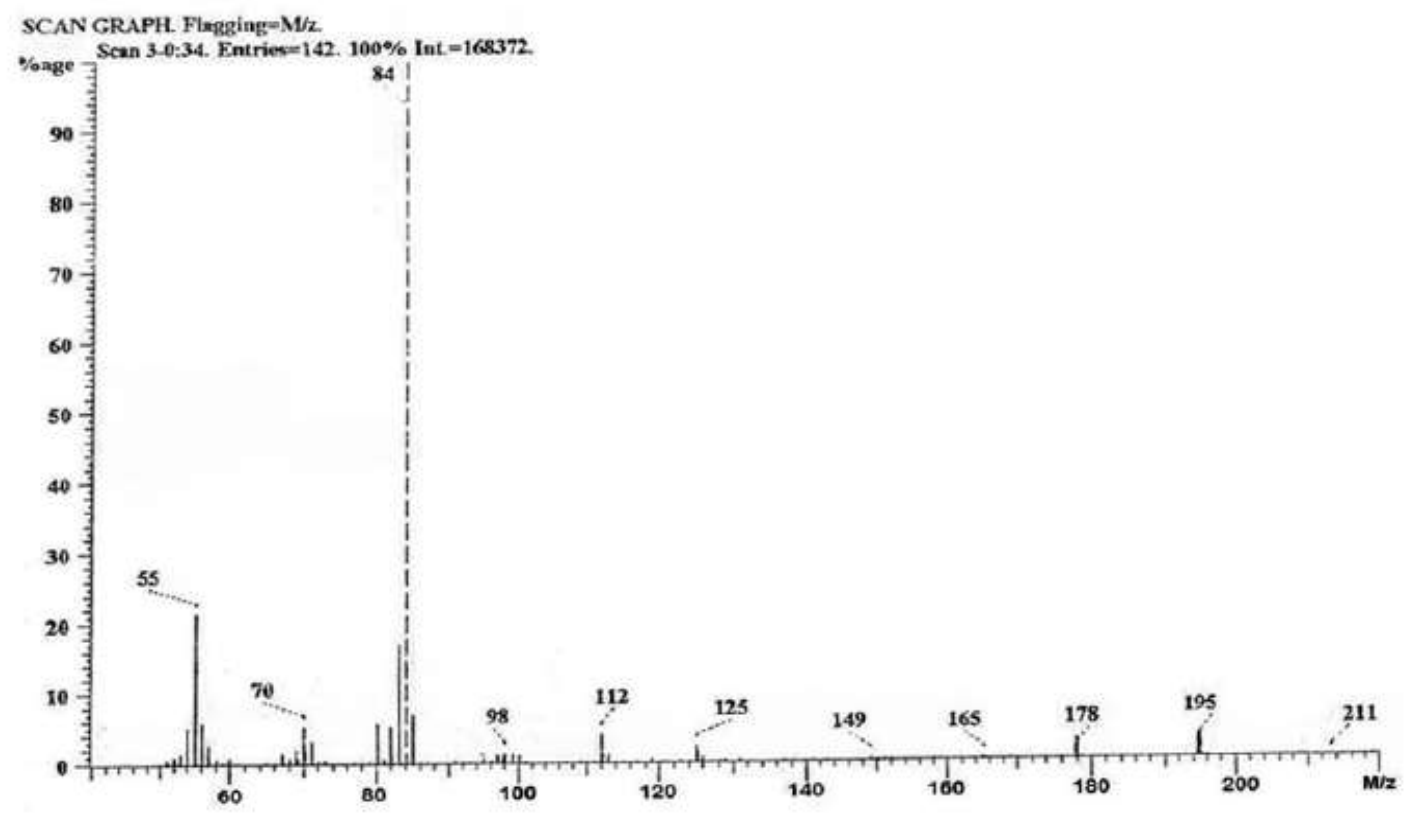

Fig.8:- Mass spectral fragmentation pattern of $\mathrm{MMMH}^{10}$<smiles>O=c1ccc(O)nn1CN1CCOCC1</smiles><smiles>O=c1ccc(O)n[nH]1</smiles><smiles></smiles>

\section{References:-}

1. Kamiya et al,Natl.Inst.Hug.Scis.,Tokyo,Japan,Yakugaku Zasshi,1966,86,1099.

2. Hellmann,Heinrich,Losehmann,Isolde,Univ.TubingenGermany,Chem.Ber.,1956,89,594.

3. Lan,P.,Chen,W.N.,Xiao,G.K.,Sun,P.H.and Chen,W.M.,Bioorg.Med.Chem.Lett.,2010,20,6064.

4. Raparti,V.,Chitre,T.,Bothra,K.,Kumar,V.,Dangre,S.,Kanchane,C.,Gore,S.andDeshmane,B.,Eur.J.Med.Chem.,20 $09,44,3954$.

5. Wang,L.J.,Li,W.W.,Yang,S.Y and Yang,L.,Acta Cryst.,2012,E68,01235.

6. Nakamoto,K. Infrared Spectra of Inorganic and Coordination Compounds, Wiley Interscience: New York; 1970.

7. Rathakrishnan,S.,AbdulJameel,A.,Syed Ali Padusha,M.,Int.J.Scientific and Research Publications,2014,Vol.4,(7),pp.1-8. 
8. Sethi,R.,Arora,S.,Jain,N.,Jain,S.,J.Pharmaceutical Technology Research

and Management,2015,Vol.3,(2),pp.97-111.

9. SumanBala,NehaSharma,AnuKajal,SunilKamboj and Vipin Saini,Int.J.Med.Chem,2014,pp.1-15.

10. AtiatS.Barakat,Mohamed S. El-Attar ,Int.J.Advances in Pharmacy,Biology and Chemistry,2015,Vol.4(2).pp.439-442. 